\title{
An investigation into the influence of micro structures on nucleate boiling processes
}

\author{
A. Schubert ${ }^{1}$, M. Zinecker ${ }^{1}$, M. Hackert-Oschätzchen ${ }^{1}$, \\ M. Lausberg ${ }^{2} \&$ A. Schulz ${ }^{3}$ \\ ${ }^{1}$ Technische Universität Chemnitz, Germany \\ ${ }^{2}$ cool tec Electronic GmbH, Germany \\ ${ }^{3}$ Strukturtechnik UG, Germany
}

\begin{abstract}
From the prior art it is known that a selective modification of heat transfer surfaces may lead to an improvement of heat transfer rates. For evaporation processes, often the heat transfer surfaces are roughened, coated with porous material or structured by electro-deposition. In this study micro structures are investigated to increase the heat transfer coefficient for heat transfer by nucleate boiling. Applying micro milling and sand-blasting, different micro structures are machined in aluminum plates. A specially developed test bench is used for measuring the heat transfer coefficients for different heat fluxes. The experimental setup and the experimental procedure are described in this paper. By comparing the measurement results it is analyzed as to which structures are most appropriate for heat transfer by nucleate boiling.
\end{abstract}

Keywords: nucleate boiling, heat transfer, micro structures, micro manufacturing technologies, experimental verification.

\section{Introduction}

Because of the rapid development in micro electronics with high heat flux dissipation, new cooling technologies become more and more important. The challenge is to remove large amounts of heat from small areas at moderately low wall superheats [1].

One promising technology is evaporative cooling, which is based on the principle of continuous boiling. For an effective heat transfer with reduced wall superheats several attempts were investigated over the last decades. It is 
well known that a modification of the evaporation surfaces leads to an influence on heat transfer. The aim is to increase the number of active nucleation sites for bubble formation and the heat transfer efficiency.

A relatively simple and easy-to-implement method to improve heat transfer is roughening the heating surface [2-4]. Processes for roughening are, for example, sandblasting, grinding, rolling or turning.

Another way to achieve high nucleation site densities is coating the heating surface with porous material. Liter and Kaviany [5] showed, that with sintered copper structures the surface superheat to start nucleate boiling is about 2 to 2.5 times lower than that of a smooth surface.

Other research is dedicated to study the influence of defined micro structures, for example micro cavities or micro columns, on the heat transfer. Defined micro structures can be generated by depositing processes or direct structuring technologies. Ustinov [6] and Mitrovic [7] performed several experiments on nucleate boiling with electrodeposited micro pins made by copper. The results demonstrated that in selected cases the heat transfer coefficient is about 18 times higher in comparison to a smooth copper surface.

Shoji and Tagaki [8] have examined the influence of circular micro cavities on the formation of bubbles with distilled water. The measurement results showed a continuous bubble formation with low wall superheats for cylindrical and re-entrant cavities.

Chu et al. [9] investigated experimentally the influence of different cylindrical pin structures in silicon surfaces on the critical heat flux during boiling with high purity water. They found that an increase of the critical heat flux density up to $160 \%$ can be achieved, compared to an unstructured surface.

In this paper the influence of micro structures on nucleate boiling is analyzed. The micro structures are generated with micro milling and sand blasting. Using a special test bench the heat transfer coefficients are determined and compared with the characteristics of unstructured surfaces.

\section{Modifying the heat transfer surfaces}

As already mentioned, heat transfer with nucleate boiling can be influenced by micro structured surfaces. In this paper micro columns and roughened surfaces were selected, for the experimental studies.

Micro milling was applied to fabricate micro columns in aluminum. For this an end mill made of solid carbide with a diameter of $200 \mu \mathrm{m}$ was used. First, lines in x-direction were processed with a center distance of $400 \mu \mathrm{m}$. Then the process was repeated in y-direction. The surface to be machined was $100 \mathrm{~cm}^{2}$.

In figure 1 the height profile of the milled micro columns is presented, measured with the 3D-laser scanning microscope Keyence VK-9700.

Shown is a section of the plate with four micro columns. The widths and the lengths of the micro columns are about $200 \mu \mathrm{m}$. The depths amount to $65 \mu \mathrm{m}$ in the sections of the $\mathrm{x}$-direction movement and about $90 \mu \mathrm{m}$ in the sections of the $y$-direction movement. It can be seen in the height profile that the machined surfaces are very smooth. Only at the edges of the micro structures burrs appear. 
In addition to the micro structures in itself, the burrs cause an enhancement in the effective heat transfer surface. It is expected, that the surface enlargement leads to an improvement in heat transfer. It is also possible that bubbles are formed preferred at the burrs. This can result in a further increase in heat transfer rates.

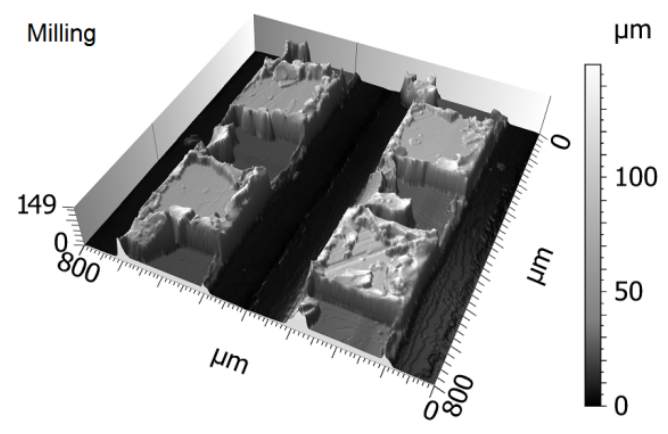

Figure 1: Height profile of the milled micro columns.

In figure 2 the height profiles of the unstructured and the sand-blasted surface are shown.
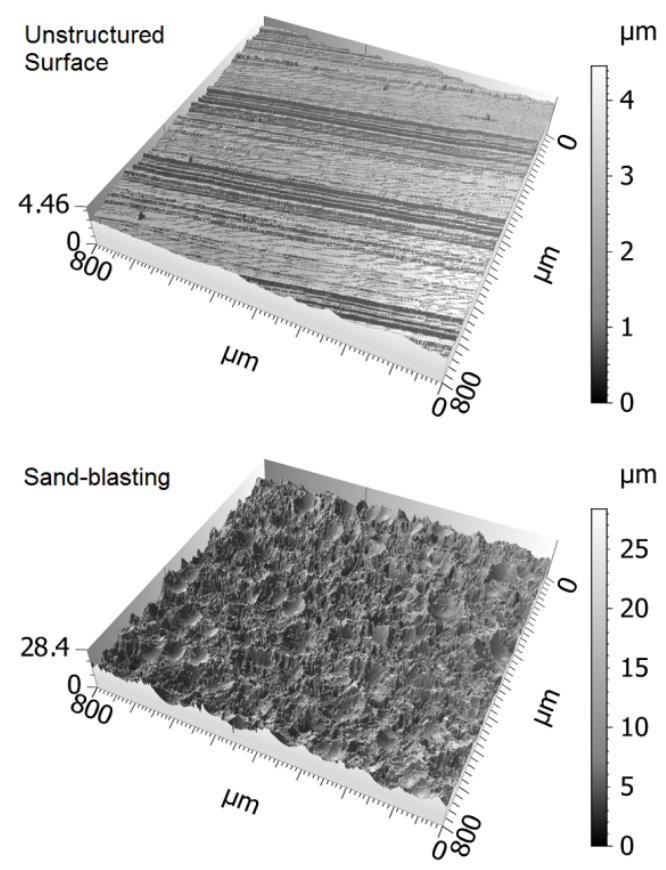

Figure 2: Height profiles of the unstructured and the sand-blasted surface. 
Using face milling the unstructured surface was prepared. The arithmetical mean deviation of the profile $\mathrm{Ra}$ is about $0.5 \mu \mathrm{m}$ and the average surface roughness $\mathrm{Rz}$ amounts to approximately $7.4 \mu \mathrm{m}$.

For roughening by sand-blasting high-grade aluminum oxide with grain sizes of about $100 \mu \mathrm{m}$ was applied. The roughness Ra was increased to about $2.4 \mu \mathrm{m}$ and $\mathrm{Rz}$ to around $32.0 \mu \mathrm{m}$. With sand-blasting a rise in number of nucleation sites is expected, which leads to an enhancement in heat transfer rates.

\section{Experimental setup}

An experimental setup was developed, based on the principle of continuous evaporation and condensation of a refrigerant in a closed system, like illustrated in figure 3.

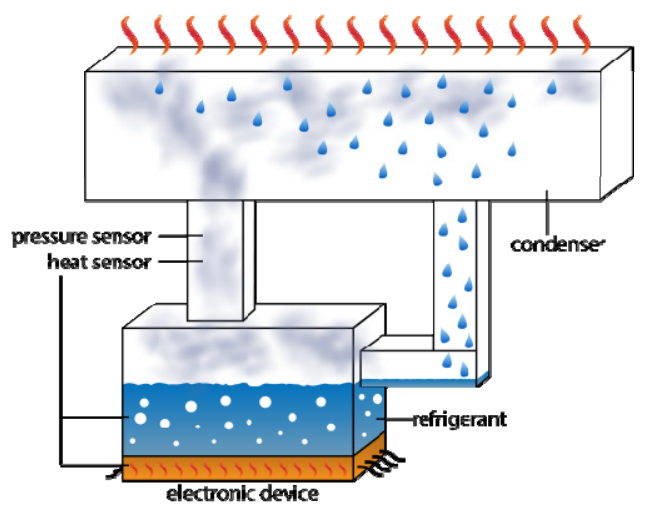

Figure 3: Scheme of the experimental setup with stationary nucleate boiling [10].

The power loss in form of heat of an electronic device is transferred to the evaporation plate by heat conduction. The evaporation plate is located in an evaporation module filled with refrigerant. If the heat flux is high enough, nucleate boiling occurs. The resulting vapor flows into a condenser, located above the module. The vapor is liquefied and flows back into the evaporation chamber. The setup corresponds to a thermosyphon, known from the literature [11].

In figure 4 a photo of the experimental setup is shown. Using an aluminum heating plate, consisting of 6 cartridge heaters, a defined heating power can be adjusted. The control of the heating elements is done by a temperature control device.

The experiments are performed with the refrigerant Solkatherm ${ }^{\circledR}$ SES36, as a non toxic and highly electrically insulating refrigerant. The filling capacity with the refrigerant was $360 \mathrm{ml}$ for all experiments. Temperature sensors were applied to measure the temperatures of the heating plate $\vartheta_{\mathrm{H}}$, the evaporator plate $\vartheta_{\mathrm{E}}$, the 
refrigerant $\vartheta_{\mathrm{R}}$ and the vapor $\vartheta_{\mathrm{V}}$, at different heating powers. From the ratio between heating power $\dot{Q}$ to surface superheat $\Delta T$ and projected heat transfer surface $A$, the heat transfer coefficient $\alpha$ can be calculated [12]:

$$
\alpha=\frac{\dot{Q}}{\Delta T \cdot A}=\frac{Q}{\Delta T}
$$

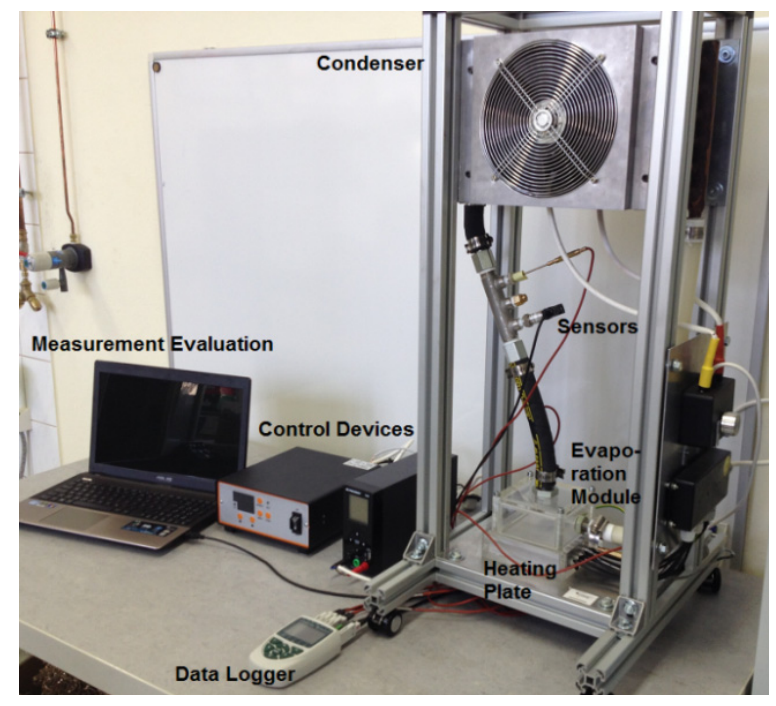

Figure 4: Photo of the experimental setup.

The projected heat transfer surface is $100 \mathrm{~cm}^{2}$ in all cases. $Q$ is the heat flux and the surface superheat is defined as the temperature difference between evaporator plate temperature and the temperature of the refrigerant. The heat transfer coefficient serves as an indicator for the efficiency of the micro structures.

Because of the strongly dependence of the thermal performance from internal pressure, a pressure sensor is placed on the vapor outlet for monitoring the pressure.

\section{Experimental results}

Experiments were performed with the different plates. In all experiments the starting internal pressure was $1 \mathrm{bar}$ and the pressure was continuously monitored. The heating power was gradually increased until the heating plate temperature reach $80^{\circ} \mathrm{C}$. At each adjusted power the temperatures of the heating plate, the evaporation plate, the refrigerant and the vapor were measured, after reaching stable temperature conditions defined in the following equation:

$$
\Delta T_{\mathrm{H}}+\Delta T_{\mathrm{E}}+\Delta T_{\mathrm{R}}+\Delta T_{\mathrm{V}}<0.5 \mathrm{~K}
$$


with:

$$
\Delta T_{\mathrm{H} ; \mathrm{E} ; \mathrm{R} ; \mathrm{V}}=\vartheta_{\mathrm{H} ; \mathrm{E} ; \mathrm{R} ; \mathrm{V}}\left(t_{\mathrm{n}}+150 \mathrm{~s}\right)-\vartheta_{\mathrm{H} ; \mathrm{E} ; \mathrm{R} ; \mathrm{V}}\left(t_{\mathrm{n}}\right)
$$

$t_{\mathrm{n}}$ is the time of measuring. The equations (2) and (3) describe that as soon as the sum of all temperature differences over 150 seconds is less than $0.5 \mathrm{~K}$, constant conditions dominate.

Then the measurements were done with decreasing heat powers in order to detect hysteresis effects. The experiments were repeated three times, and from the results, the mean values and the standard deviations were determined.

The experimental results for the unstructured plate are presented in figure 5 and figure 6 . Figure 5 shows the relation between heat flux and surface superheat for increasing and decreasing heating power. At a maximum heat flux of $23 \mathrm{~kW} / \mathrm{m}^{2}$, the surface superheat amounts to approximately $16.8 \mathrm{~K}$. It is also clear that in ascending and descending heat flux no clear hysteresis can be observed.

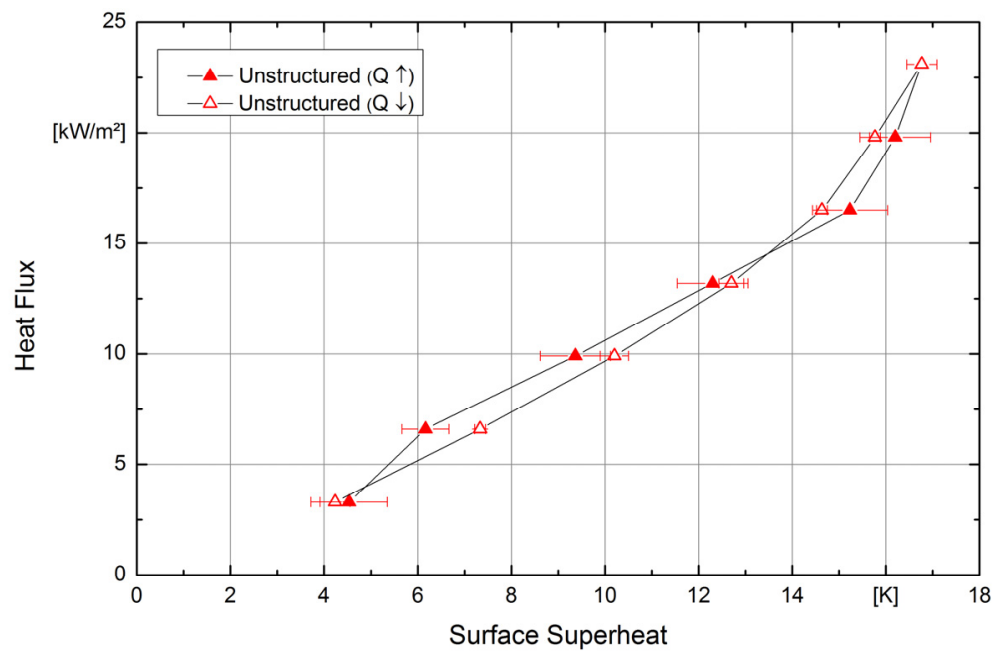

Figure 5: Surface superheat dependent to heat flux for unstructured plate.

In figure 6 the heat transfer coefficients dependent to the heat flux are presented. The maximum amount of the heat transfer coefficient is about $1380 \mathrm{~W} / \mathrm{m}^{2} \mathrm{~K}$ for a heat flux of $23 \mathrm{~kW} / \mathrm{m}^{2}$.

Following the experiments with unstructured plates, investigations on nucleate boiling with milled micro structures were performed under the same experimental regime. The surface superheat depending on the heat flux is illustrated in figure 7. 


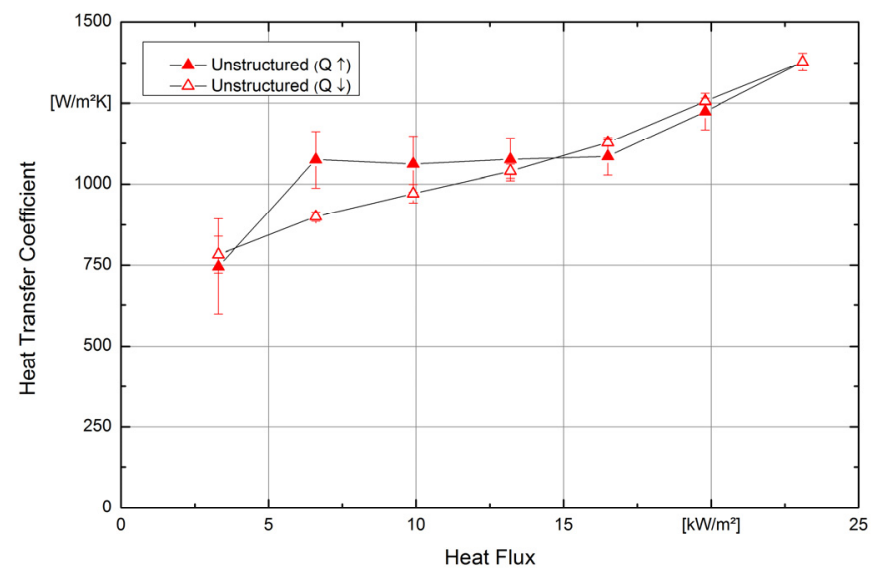

Figure 6: Heat transfer coefficient dependent to heat flux for unstructured plate.

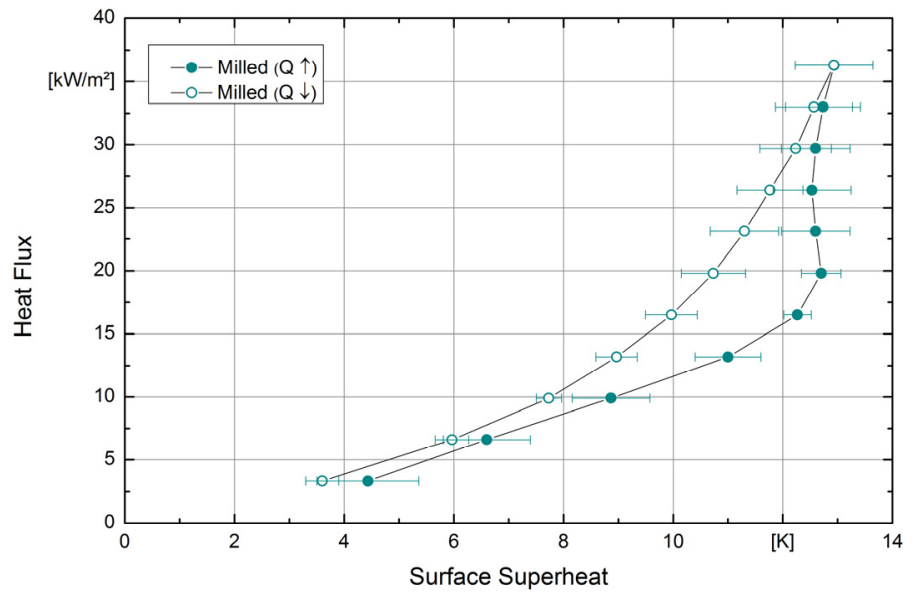

Figure 7: Surface superheat dependent to heat flux for milled micro structures.

In comparison to the unstructured surface, higher heat fluxes could be realized with the milled micro structured surface without exceeding a heating plate temperature above $80^{\circ} \mathrm{C}$. The maximum superheat is approximately $12.9 \mathrm{~K}$ for a heat flux of $36 \mathrm{~kW} / \mathrm{m}^{2}$. Hysteresis was observed between ascending and descending heat fluxes. The surface superheats are lower for descending heat fluxes.

In figure 8 the heat transfer coefficients obtained with milled micro structures are shown. 


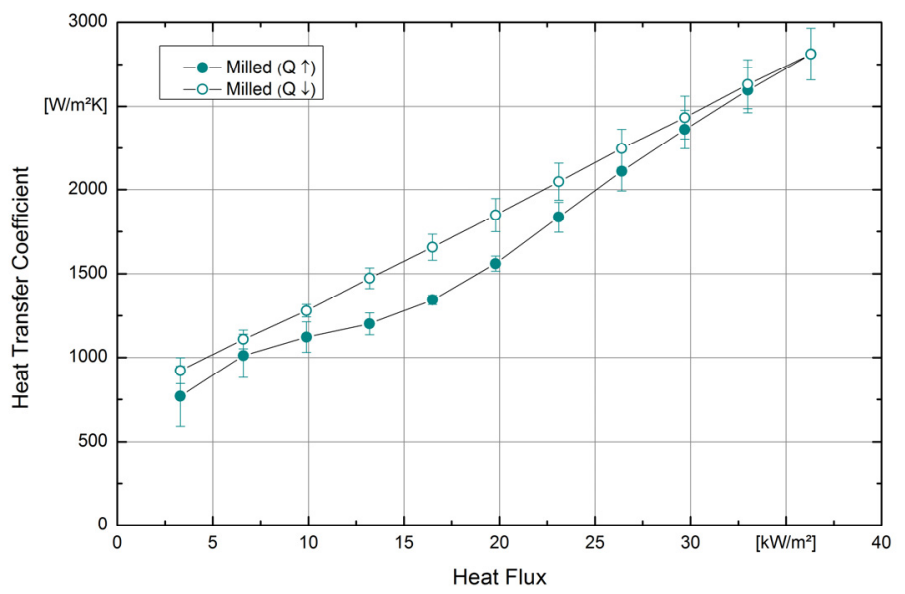

Figure 8: Heat transfer coefficient dependent to heat flux for milled surface.

The maximum heat transfer coefficient for a heat flux of $36 \mathrm{~kW} / \mathrm{m}^{2}$ is about $2810 \mathrm{~W} / \mathrm{m}^{2} \mathrm{~K}$.

In addition to the unstructured and the milled surface the heat transfer with a sand-blasted surface was investigated. The results are presented in figure 9 and figure 10. Applying a maximum heat flux of about $40 \mathrm{~kW} / \mathrm{m}^{2}$, the surface superheat does not exceed $10 \mathrm{~K}$, like illustrated in figure 9. As with the milled surface, a hysteresis could be observed for the sand-blasted surface. The surface superheat is lower with decreasing heat flux than with increasing the heat flux.

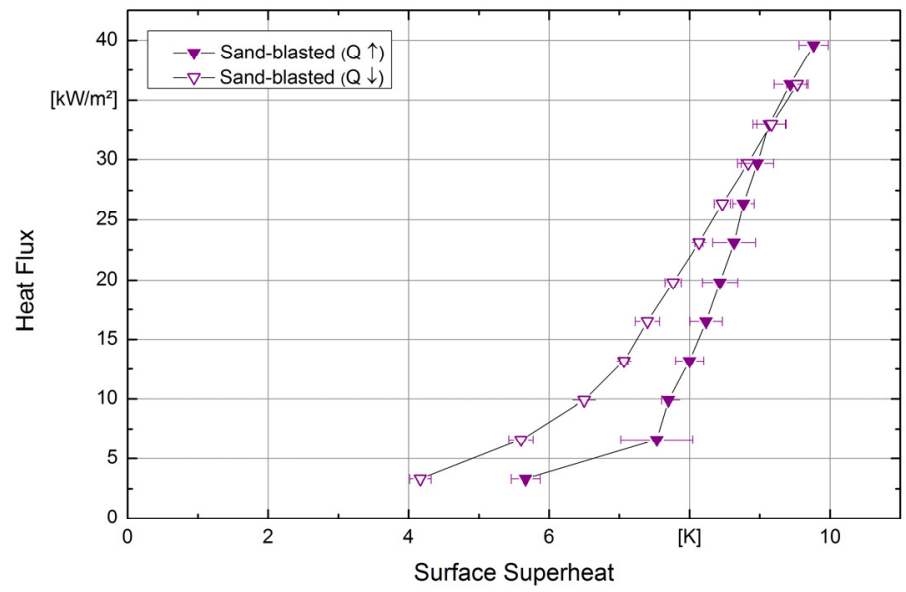

Figure 9: Surface superheat dependent to heat flux for sand-blasted surface. 
In figure 10 the heat transfer coefficients for the sand-blasted surface are shown.

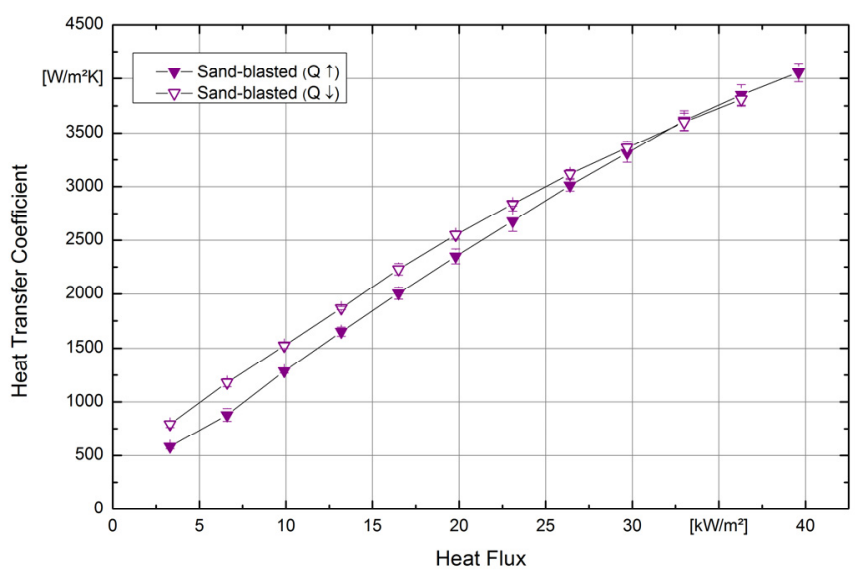

Figure 10: Heat transfer coefficient dependent to heat flux for sand-blasted surface.

A maximum heat transfer coefficient of approximately $4060 \mathrm{~W} / \mathrm{m}^{2} \mathrm{~K}$ for a heat flux of about $40 \mathrm{~kW} / \mathrm{m}^{2}$ was achieved.

The experimental results are compared in figure 11 to figure 14, for a better illustration of the effects of surface modification on nucleate boiling.

In figure 11 the superheats applying the different surfaces for an increasing heat flux are presented. It is obvious that with a modification of the surface the superheats can be significantly reduced.

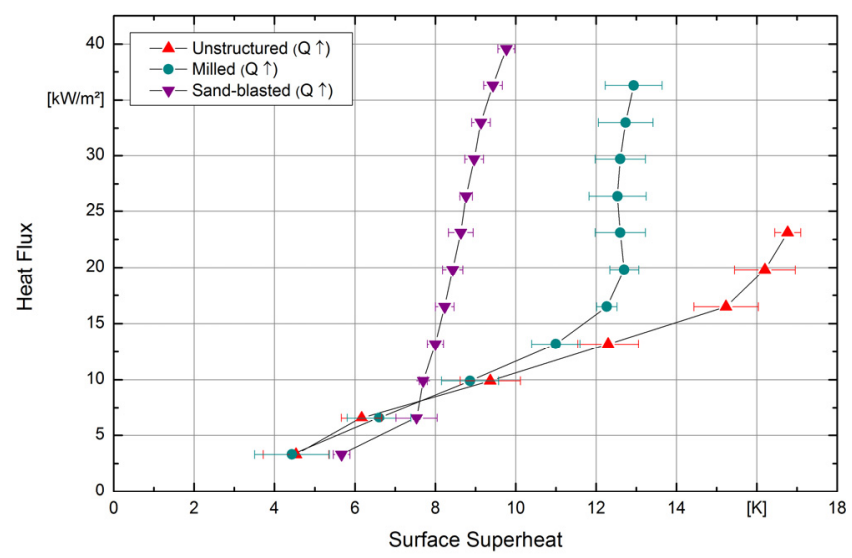

Figure 11: Surface superheat dependent to ascending heat flux for different surface properties. 
The best results were obtained with the sand-blasted plate, followed by the milled surface. As an example, the values for $23 \mathrm{~kW} / \mathrm{m}^{2}$ are compared. While the superheat for the unstructured plate amounts to approximately $16.8 \mathrm{~K}$, the superheat for the milled surface is about $12,6 \mathrm{~K}$ and for the sand-blasted only 8.6 $\mathrm{K}$. This enormous effect was also found in the descending heat fluxes, like illustrated in figure 12. In this case, the surface superheat for a heat flux of $23 \mathrm{~kW} / \mathrm{m}^{2}$ could be reduced from $16.8 \mathrm{~K}$ for the unstructured surface to about $11.3 \mathrm{~K}$ with the milled micro structures and to about $8.1 \mathrm{~K}$ with the sand-blasted surface. This represents a reduction by $33 \%$ and $52 \%$ respectively.

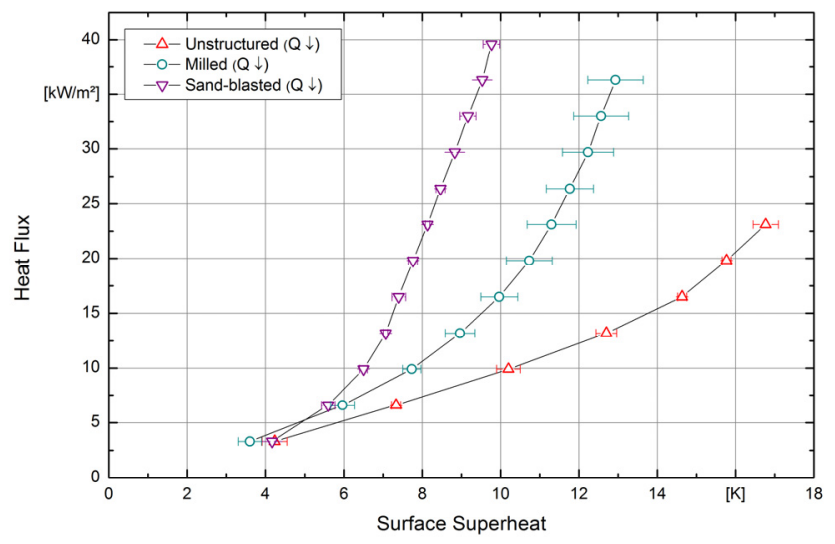

Figure 12: $\quad$ Surface superheat dependent to descending heat flux for different surface properties.

In figure 13 the heat transfer coefficients for the different surface properties with increasing heat flux are shown.

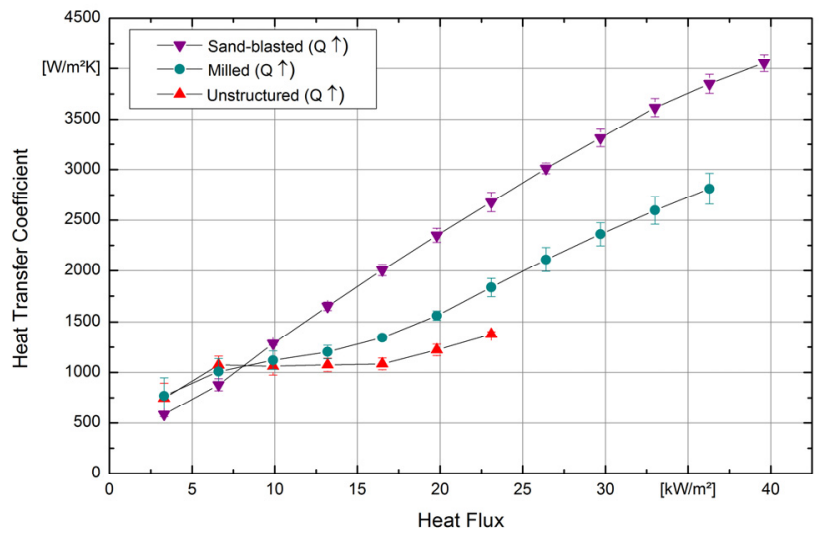

Figure 13: Heat transfer coefficient dependent to ascending heat flux for different surface properties. 
The highest heat transfer coefficients were obtained with the sand-blasted surface, followed by the milled micro structures. For a heat flux of $23 \mathrm{~kW} / \mathrm{m}^{2}$ the heat transfer coefficients are about $2680 \mathrm{~W} / \mathrm{m}^{2} \mathrm{~K}$ for the sand-blasted surface, $1840 \mathrm{~W} / \mathrm{m}^{2} \mathrm{~K}$ for the milled micro structures and $1380 \mathrm{~W} / \mathrm{m}^{2} \mathrm{~K}$ for the unstructured surface. This is equivalent to a maximum increase of the heat transfer coefficient of about 1.96 times applying a sand-blasted surface instead of an unstructured one. Even at higher heat fluxes the sand-blasted plate is characterized by the most effective heat transfer. For example, the heat transfer coefficient for the milled micro structures at $36 \mathrm{~kW} / \mathrm{m}^{2}$ is about $2810 \mathrm{~W} / \mathrm{m}^{2} \mathrm{~K}$. With the sand-blasted surface the heat transfer coefficient achieves an about 1.37 times higher value of approximately $3850 \mathrm{~W} / \mathrm{m}^{2} \mathrm{~K}$.

In figure 14 the heat transfer coefficients with decreasing heat flux are presented. Also in this diagram, the effect of surface modification to increase heat transfer rates in nucleate boiling is confirmed. For a heat flux of $23 \mathrm{~kW} / \mathrm{m}^{2}$ an improvement in heat transfer coefficient by a factor of 1.49 for the milled surface and 2.06 for the sand-blasted plate was realized, in comparison to the unstructured surface.

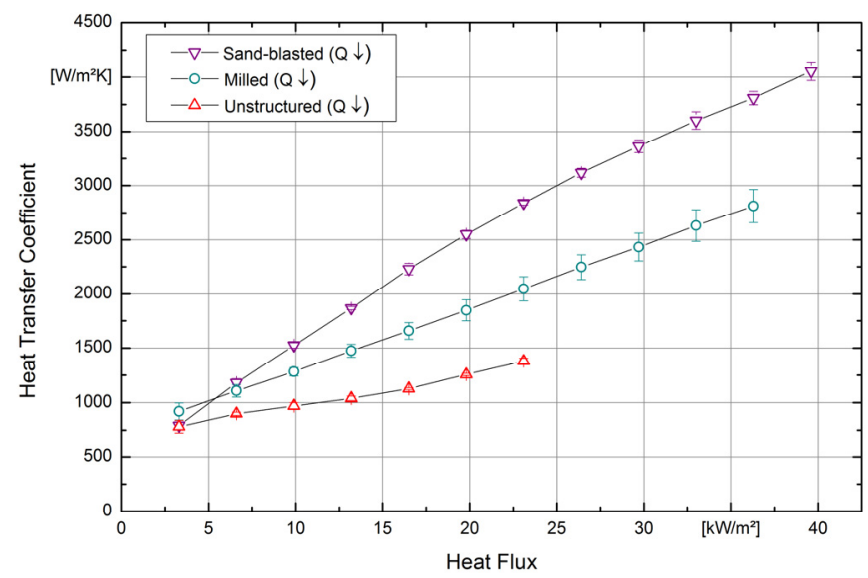

Figure 14: Heat transfer coefficient dependent to descending heat flux for different surface properties.

\section{Conclusion}

In this paper the influence of micro columns and sand-blasted surfaces on heat transfer rates in nucleate boiling was analyzed and compared with an unstructured surface. For this, an experimental setup was developed. Due to modifying the heat transfer surface, higher heat transfer coefficients and lower surface superheats were realized. Especially the sand-blasted surface showed promising heat transfer characteristics. In comparison to the unstructured surface about two times higher heat transfer coefficients were obtained. Furthermore it 
was found, that hysteresis effects between ascending and descending heat flux occur for the milled and the sand-blasted micro structures.

In further research, the impact of other micro structures on heat transfer with nucleate boiling will be examined.

\section{Acknowledgement}

This project is funded by the Federal Ministry of Economics and Technology, following a decision of the German Bundestag.

\section{References}

[1] Hosseini, R., Gholaminejad, A. \& Jahandar, H., Roughness Effects on Nucleate Pool Boiling of R-113 on Horizontal Circular Copper Surfaces, World Academy of Science, Engineering and Technology, 55, pp. 679-684, 2011.

[2] Jones, B.J., McHale, J.P. \& Garimella, S.V., The Influence of Surface Roughness on Nucleate Pool Boiling Heat Transfer, Journal of Heat Transfer, 131, 2009.

[3] McHale, J.P. \& Garimella, S.V., Bubble nucleation characteristics in pool boiling of a wetting liquid on smooth and rough surfaces, International Journal of Multiphase Flow, 36(4), pp. 249-260, 2010.

[4] McHale, J.P. \& Garimella, S.V., Nucleate boiling from smooth and rough surfaces - Part 2: Analysis of surface roughness effects on nucleate boiling, Experimental Thermal und Fluid Science, 44, pp. 439-455, 2013.

[5] Liter, S.G., \& Kaviany, M., Pool-boiling CHF enhancement by modulated porous-layer coating: theory and experiment, International Journal of Heat and Mass Transfer, 44, pp. 4287-4311, 2001.

[6] Ustinov, A., Nucleate pool boiling on microstructured surfaces, PhD-Thesis, University of Paderborn, 2008.

[7] Mitrovic, J., How to create an efficient surface for nucleate boiling? International Journal of Thermal Sciences, 45(1), pp. 1-15, 2006.

[8] Shoji, M. \& Takagi, Y., Bubbling features from a single artificial cavity, International Journal of Heat and Mass Transfer, 44, pp. 2763-2776, 2001.

[9] Chu, K.-H., Enright, R. \& Wang, E.N., Structured surfaces for enhanced pool boiling heat transfer, Applied Physics Letters, 100(24), 2012.

[10] Schubert, A., Zinecker, M., Hackert-Oschätzchen, M., Lausberg, M. \& Schulz, A., Determining of micro structuring technologies for nucleate boiling surfaces, Proceedings of the 8th World Conference on Experimental Heat Transfer, Fluid Mechanics and Thermodynamics, 2013.

[11] Reay, D., McGlen, R. \& Kew, P., Heat pipes: Theory, design and applications, Butterworth-Heinemann, 2013.

[12] Böckh, P. von, Wärmeübertragung: Grundlagen und Praxis, Springer Verlag: Berlin, 2004. 